\title{
Forgiveness as a Mediator for the Relationship between Spirituality and Posttraumatic Growth in Aceh Conflict Victims, Indonesia
}

\author{
Hafnidar, L. Chang, and H. Lin
}

\begin{abstract}
People in Aceh are still suffering from a highly traumatic experience of Aceh conflict. As a religious community, Acehnese people believe that forgiveness is righteous. The purpose of the present study was to examine the mediational role of forgiveness on the relationship between spirituality and posttraumatic growth (PTG). Two hundred sixty-eight participants were recruited to complete the Posttraumatic Growth Inventory (PTGI), Heartland Forgiveness Scale (HFS), and the Spiritual Transcendence Scale (STS). Results based on Sobel analyses revealed that forgiveness mediated the relationship between spirituality and PTG. Implications of these findings for future research on PTG and forgiveness are discussed.
\end{abstract}

Index Terms-posttraumatic growth, forgiveness, spirituality.

\section{INTRODUCTION}

For many people, forgiveness is a deeply spiritual theme [1]. The Al-Quran cites many passages concerning forgiveness, for example, the Al-Quran (22:24) says, "and let them pardon and overlook, would you not like that Allah should forgive you? and Allah is Forgiving and Merciful" [2] According to the Al-Qu'ran (42:43), individuals should acquire to be patient in adversity and forgive [2]. Therefore, the Muslim people who did not follow the teachings of the Al-Quran will be difficult to forgive. Beside, according to Hadist Bukhari and Muslim riwayat, prophet Muhammad says that Allah will raise the glory of individuals who are able to forgive, in other words the people who are willing to forgive would be given power by God to transform into a higher level of man or having growth in their life [3].

Emmons suggested that forgivingness may be a component of spiritual intelligence because many of these personality and behavioral qualities are conceptually [4]. Consistent with some views of spirituality. Lois found that who reported more spirituality and more self-forgiving attitude reported less mood disturbance and a better quality of life, in contrast, participants who reported more self-blame reported more mood disturbance and poorer qulity of life [5].

A recent study considered the benefit finding of forgiveness. McCullough et al asked college students to think

Manuscript received February 25, 2012; revised April 7, 2012.

This work was supported in part by the Asia University Taiwan. The first author would like to express her sincere gratitude to Hsiu-Chen Lin, $\mathrm{PhD}$ and Li-Jung Chang, PhD as the main supervisor of the master research.

Hafnidar is master student with the Department of Psychology, Asia University Taiwan, 500, Liufeng Rd, Wufeng, Taichung, Taiwan 41354. She on leave from the Malikussaleh University, Lhokseumawe Aceh, Indonesia as a lecturer (e-mail: nidar.psy@gmail.com).

L. Chang and H.Lin are with with the Department of Psychology, Asia University Taiwan, 500, Liufeng Rd, Wufeng, Taichung, Taiwan 41354. of the most recent time they were hurt in a relationship and to then participate in one of three writing conditions: writing about traumatic aspects of the experience, writing about positive aspects or benefits of the experience, or writing about an unrelated topic. Individuals in the benefit finding condition demonstrated significantly higher levels of forgiveness than those in the control and traumatic features conditions. This study suggests that cognitive processing may explain the role of benefit finding as facilitating forgiveness in an experimental environment, consistent with the conceptual links between the constructs described in both domains of theoretical literature [6].

Several study examined spirituality and several religious variables have been linked to increased PTG, including existential openness, intrinsic religiousness, religious participation and religious coping [7]-[9]. Spirituality is also an indicator of personal growth in person-centered counseling with Malay clients [10]. PTG has been defined as a positive psychological change experienced as a result of the struggle with highly challenging life circumstances [11]. It may include a perception of increased personal strength, changing one's views about life, and feeling closer to others [12]. While spirituality as a motivational trait perspective that conceptualizes spirituality as a quality that originates within the body itself and that propels the organism [13]. This theme called as spiritual transcendence, refers to the capacity of individual to stand outside of their immediate sense of time and place to view life from a larger, more objective perspective [13].

Previous empirical research found that PTG involves alterations in self (such as new directions or enhanced spirituality and religiosity) and changes in relationships with others, forgiveness as the release of negative feelings toward another and the adoption of positive attitudes might form a causal link between the offense and later growth, in fact, a prominent model of forgiveness suggests that individuals find an altered sense of purpose, one component of posttraumatic growth, through engaging in forgiveness [9].

Therefore, the relation between spirituality and PTG seems not to be direct: higher level on PTG are interrelated with spirituality, such that spirituality predict forgiveness to have PTG. These findings support the notion that whereas spirituality are related to PTG, other variables more related to forgiveness may play an important role in the spirituality PTG relationship. It is plausible that spirituality variables might lead people to have forgiveness and then to have some degree to increase their level of PTG.

In fact, there are also some reasons to consider a mediation model in which spirituality influences PTG through forgiveness. First, forgiveness have been found to be associated to spirituality [14]-[19]. Second, forgiveness have 
shown to be a significant predictor of PTG [9], [21]. So, these findings are according to the criterion necessary for forgiveness to be considered a potential mediator. Third, there is accumulative evidence to suggest that people with higher spirituality higher levels of PTG [22]-[26]. Hence, analyzing this hypothesis is important in understanding why some conflict victims have long-lasting PTG while others do not. Therefore, the present study has two objectives. First, we sought to examine the relations among spirituality, forgiveness and PTG. Secondly, consistent with the proposed mediation model, we examine the extent to which forgiveness might mediate the influence of spirituality variables on PTG with conflict victims in religious communities.

\section{METHOD}

\section{A. Participant}

Two hundred sixty-eight Aceh conflict victims completed questionnaires for this study. Sixty-seven point five percent of the final sample were women, $32.5 \%$ were men. Their ages ranged from 18 to 60 years $(\mathrm{M}=34.81, \mathrm{SD}=10.45)$. Fourteen point six percent participants were single, $72.8 \%$ were married and $12.7 \%$ were widow/widower. The number of participants who drop out from Elementary School were $42.2 \%, 1.1 \%$ were graduated from Elementary School, $28 \%$ were graduated from Junior High School, 18.3\% were graduated from Senior High School, 1.9\% were graduated from College and $8.6 \%$ were uneducated. All participants declared themselves as Muslim as well as Acehnese. Thirty-four point three percent participants reported themselves as primary victims (direct) and $65.7 \%$ as secondary victims (indirect).

\section{B. Material}

All of measures are described below:

Demographic/background information. The Basic Demographic Questionnaire was developed by the researcher and included questions regarding age, gender, educational level, religious affiliation.

Posttraumatic Growth Inventory (PTGI). The Posttraumatic Growth Inventory (PTGI; Tedeschi \& Calhoun, 1996) is a 21-item self-report measure of positive outcomes following traumatic experiences. Each item is rated using a 6-point Likert scale. The total score can range from 0 to 105 , with higher scores indicating greater growth. The five PTGI subscales were developed using principal components analysis on data from 604 college students [12]. Internal consistency alpha were found for relating to others $(\alpha=.85)$, new possibilities $(\alpha=.84)$, personal strength $(\alpha=.72)$, spiritual change $(\alpha=.85)$, appreciation of life $(\alpha=.67)$ and for PTGI overall $(\alpha=.90)$. The test-retest reliability $(\alpha=.71)$ over 2 months has also been reported based on the sample of university students in the original study [12]. Cronbach's alpha of the PTGI subscale in the present sample were acceptable in reliability: personal strength $(\alpha=74)$, new possibilities $(\alpha=.77)$, appreciation of life $(\alpha=.66)$, relating to others $(\alpha=.71)$, spiritual change $(\alpha=.73)$ and for PTGI overall $(\alpha=.85)$.
Heartland Forgiveness Scale (HFS). The Heartland Forgiveness Scale (HFS) was developed by Thompson et al to measure one's forgiveness level with 18 items [27]. HFS is a 7-point Likert-type scale ranging from "almost always false than true"(1) to "almost always true of me"(7). The HFS total scale and subscale scores are calculated by summing the items on each scale, with the nine negatively worded items (2, $4,6,7,9,11,13,15$, and 17) being reverse-scored. Higher scores on each subscale reflect a higher level of forgiveness in each domain. The HFS has been reported to have adequate psychometric properties in previous studies [27]. Internal consistency alpha were found for forgiveness of self $(\alpha=.75)$, for forgiveness of others $(\alpha=.78)$, for forgiveness of situation $(\alpha=77)$. Cronbach's alpha for all subscales are satisfactory $(\alpha=86)$, and re-retest reliability for all subscales are acceptable $(\alpha=.67)$. Cronbach's alpha of the HFS subscale in the present sample were acceptable in reliability: forgiveness of self $(\alpha=.82)$, forgiveness of others $(\alpha=.84)$, forgiveness of situations $(\alpha=.85)$ and for HFS overall $(\alpha=.29)$.

Spiritual Transcendence Scale (STS). The Spiritual Transcendence Scale is a 24-item scale consisting of three subscales [13]. Each item is rated using a 5-point Likert scale with rating ranging from 1 to 5 . Internal consistency for the three subscales of the STS were .97, .97, and .94 for connectedness, universality, and prayer fulfillment scales, and the test-retest reliability (.91) were reported by Piedmont (1999). Cronbach's alpha of the STS subscale in the present sample were were acceptable in reliability: $.84, .78, .77$ for connectedness, universality, prayer fulfillment and .88 for STS overall.

\section{RESULT}

\section{A. Descriptive Analyses}

Pearson correlations, means, and standard deviations of the different scales used are presented in table 1, revealed that spirituality was significantly positively related with both forgiveness $(r=.218, p<.001)$ and PTG $(r=.773, p<.001)$. Forgiveness also significantly positively related with PTG (r $=.155, \mathrm{p}<.005)$.

\section{B. Test of Mediation}

A mediator model of the relation between spirituality and PTG is proposed according to Baron and Kenny [28]. The mediator model implies that forgiveness mediated the association between spirituality and PTG. Preliminary analyses indicated spirituality and PTG met the criteria for mediational analysis.

To determine whether forgiveness were a mediator, the following steps identified were completed: First, the predictor variable (spirituality) must be related to the mediator variable (forgiveness). Second, the predictor variable must be related to the outcome variable (PTG). Third, the mediator variable must be related to the outcome variable. Fourth, after controlling for the effects of the mediator on the outcome, the relation between the predictor and the outcome must be significantly decreased. To determine whether the reduction could be considered significant, the Sobel test was used [29]. We conducted a series of three regressions to test 
for a mediation effect of forgiveness on the relationship between spirituality and PTG. First, forgiveness were regressed on spirituality $(b=.218, p<.001)$. Second, the predictors, spirituality, were regressed on PTG $(b=.77, p$ $<.001)$. Spirituality contributed a significant amount of variance to PTG. Third, forgiveness was simultaneously regressed on spirituality $(b=.19, \mathrm{p}<.001)$. Finally, the regression model contributed a significant amount of variance to PTG (59\%). The mediational role of forgiveness on the relationship among spirituality and PTG are represented in Figs. 1.

As shown in Fig. 1, the beta weight when spirituality was regressed alone on posttraumatic growth was .77. When forgiveness were entered into the equation, the beta weight dropped from .77 to .74 . Sobel test was significant $(z=2.53$, $\mathrm{p}<.01)$ indicating that forgiveness only partially mediated the relationship between spirituality and PTG.

TABLE I: MEANS, STANDARD DEVIATIONS AND CORRELATIONS BETWEEN DIFFERENT MEASURES

\begin{tabular}{|c|c|c|c|c|c|c|c|}
\hline & & 1 & 2 & 3 & 4 & 5 & 6 \\
\hline 1. & PTG & 1 & & & & & \\
\hline 2. & Forgiveness & $.195^{* *}$ & 1 & & & & \\
\hline 3. & $\begin{array}{c}\text { Forgiveness of } \\
\text { self }\end{array}$ & $.175^{* *}$ & $.882 * *$ & * 1 & & & \\
\hline 4. & $\begin{array}{c}\text { Forgiveness of } \\
\text { others }\end{array}$ & $.208 * *$ & $.926 * *$ & $* .742 * *$ & 1 & & \\
\hline 5. & $\begin{array}{r}\text { Forgiveness of } \\
\text { situations }\end{array}$ & $.155^{*}$ & $.917 * *$ & $.683 * *$ & * $.801 * *$ & * 1 & \\
\hline 6. & Spirituality & $.773 * *$ & $.218 * *$ & $.166^{* *}$ & $.208 * *$ & $.218 * *$ & 1 \\
\hline M & & 93.21 & 115.65 & 38.42 & 38.45 & 45.17 & 99.43 \\
\hline SD & & 8.81 & 8.12 & 2.8 & 3.09 & 3.50 & 10.57 \\
\hline
\end{tabular}

$* \mathrm{p}<0.05$

$* * \mathrm{p}<0.01$.

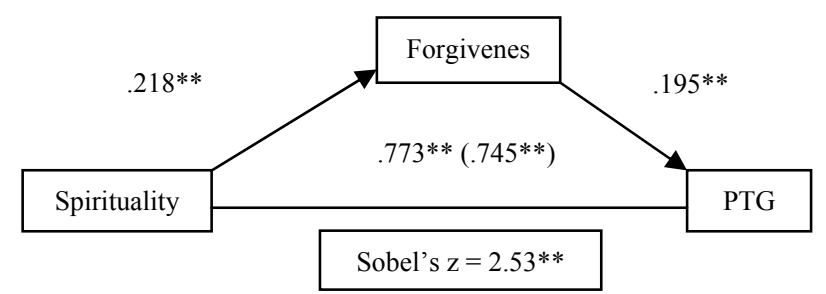

Fig. 1. Mediating role of forgiveness in the relationship between spirituality and PTG. Numbers outside parentheses refer to simple correlations. Numbers within parentheses refer to standardized path coefficients.

\section{DISCUSSION}

The primary aim of our study was to analyze the relationship among spirituality, forgiveness and PTG. Besides, we sought to determine whether forgiveness mediate the relationship between spirituality and PTG. Consistent with findings obtained in previous studies, results of this study indicated that greater spirituality were significantly associated with higher PTG [22]-[26]. Milam et al found a positive correlation between religiosity (defined by the authors as participation in organized religion) and PTG within their sample (although the religiosity-PTG relation was non-significant after controlling for other variables - i.e., age, elapsed time since event, depression, and substance abuse - in a regression model) [23]. In a later study, Milam et al found that youth who identified with a religion were more likely to report higher levels of PTG [24]. Additionally, Vaughn et al. discovered that all three subscales of the SRGS-A (cognitive/affective, social, and religious) were significantly positively associated with the use of religious coping [26]. Laufer and Solomon examined PTG among Jewish Israeli youth and split the youth into groups based on their level of religiosity [22]. In general, the authors concluded that youth who identified as religious reported more PTG than those who identified as secular or traditional in their beliefs and practices. Specifically examining PTGI subscales, the authors found that spiritual change and appreciation of life were the highest among religious compared to traditional youth (who were higher than secular youth), religious and traditional youth were higher than secular youth on relating to others, and traditional were higher than religious and secular youth on new possibilities and personal strength. In addition, religious youth reported higher subjective exposure (i.e., fear) and were exposed to fewer negative life events than secular youth. Our result support this point suggesting that people should be encouraged to develop their sipirituality to find growth after traumatic event in their life. Similarly, the people who tended to have higher forgiveness experienced higher levels of PTG. Several study found that forgiveness has possitive and significant associations with PTG [9], [21]. Previous empirical research found that PTG involves alterations in self (such as new directions or enhanced spirituality and religiosity) and changes in relationships with others, forgiveness as the release of negative feelings toward another and the adoption of positive attitudes might form a causal link between the offense and later growth, in fact, a prominent model of forgiveness suggests that individuals find an altered sense of purpose, one component of posttraumatic growth, through engaging in forgiveness [9]. Beside, several research has shown that religiosity is related to trait forgivingness [14]- [16], [30]. Tsang et al suggested that religion might be used to either encourage forgiveness or justify holding grudges, depending on the nature of one's religion [16]. Several study found that religious individuals are more likely to value forgiveness than those who are not religious [17]-[20], [31]-[32]. Our findings also support this argument in Aceh conflict fictims sample.

Mediational analysis result supported that forgiveness as a mediator for the relationship between spirituality and PTG. Our findings sudgest that people who higher level on spirituality are more likely to forgive others, self and situations wich in turn contributes to PTG. Futhermore, whereas educational and therapeutic effort to increase spirituality may increase PTG in conflict victims. Spirituality will drive people to love forgiveness and then to have PTG. The relationship between spirituality and forgiveness is evident in that forgiveness is heavily rooted in many theologies. As a Muslim religious community, Acehnese people beliefe that forgiveness would bring them to PTG after traumatic experience. The relationship between religion and forgiveness is evident in that forgiveness is heavily rooted in many theologies. The Al-Quran cites many passages concerning forgiveness, for example, the Al-Quran (22:24) says, "and let them pardon and overlook. Would you not like that Allah should forgive you? And Allah is 
Forgiving and Merciful”. According to the Al-Qu'ran 42:43, individuals should acquire to be patient in adversity and forgive [2]. Therefore, the Muslim people who did not follow the teachings of the Quran will difficult to forgive. Our results sudgest that spirituality alone is not key factors in relationship of religious community such as aceh conflict victims, another avenue of interventions migh be to increase the forgiveness. In this line, Harris and Thoresen; Toussaint and Webb found that forgiveness contributed to increased mental and physical health [33]-[34]. PTG and PTG related constructs were found to be positively related to a wide range of such positive mental health resources: positive affect, optimism, hope, self-esteem, competency beliefs, and quality of life (only after controlling for posttraumatic stress reactions [35].

Several limitations of this study are acknowledged. First, this study only examined the role of forgiveness rather than the role of forgiveness of self, forgiveness of others and forgiveness of situations. The use of a correlational design in this research also limits the interpretations so that we cannot know for certain the direction of causality of the variables under research. Despite these limitations, our study provides some empirical support for the mediating influence of forgiveness on the relation between spirituality and PTG. It seems likely that PTG is enhanced by some combination of forgiveness and spirituality that yield personal benefit at a later point. In this sense, this research lends credence to those clinical interventions to increase PTG that focus in improving both aspects in conflict victims. Future research should thus aim to assess the potential benefits, other than PTG, gained by engaging in forgiveness, for example mental health; examine the differences between victims who did versus did not meet diagnostic criteria for PTSD, those with versus without comorbid diagnoses (e.g., personality disorders).

\section{REFERENCES}

[1] D. E. Davis, J. N. Hook, E. L. Worthington, D. R. Van Tongeren, A. L. Gartner, D. J. Jennings, and L. Norton, "Relational Spirituality and Dealing With Transgressions: Development of the Relational Engagement of the Sacred for a Transgression (REST) Scale," International Journal for the Psychology of Religion, vol. 20, pp. 288-302, Oktober 2010.

[2] R I. Depag, Alquran dan Terjemahnya, Jakarta: CV Toha Putra Semarang, 1999, pp. 335-488.

[3] M. B.S. Al-Utsaimin, Syarah Hadist Arba'in, Pustaka Ibnu Katsir, 2010, pp. 43

[4] R. A. Emmons, "Is spirituality an intelligence? Motivation, cognition, and the psychology of ultimate concern," International Journal for the Psychology of Religion, vol. 10, pp. 3-26, November 2009.

[5] F. Lois C, R. B Catherine, C. Jenny, L. T. Yee, K. Mamta, R. Mothaffar F, D. Mario F, and E. Richard "Self-blame, Self-forgiveness, and Spirituality in Breast Cancer Survivors in a Public Sector Setting," J Canc Educ, vol. 25:343-348, February 2010

[6] M. E. McCullough, L. M. Root, and A. D. Cohen, "Writing about the benefits of an interpersonal transgression facilitates forgiveness," Journal of Consulting and Clinical Psychology, vol. 74, pp. 887-897, 2006.

[7] P. A. Linley and S.Joseph, "Positive change following trauma and adversity: A review," Journal of Traumatic Stress, vol. 17, pp. 11-21, 2004.

[8] A. Shaw, S.Joseph, and P. A. Linley, "Religion, spirituality, and posttraumatic growth: A systematic review," Mental Health, Religion and Culture, vol. 8, 1-11, januari 2005.

[9] R. D. Enright and R. P. Fitzgibbons, "Helping clients forgive: An empirical guide for resolving anger and restoring hope," Washington, DC: American Psychological Association, 2000.
[10] M. Mardiana, H. M., Halimatun, and A. S. Asnarulkhad, "Person-centered counseling with Malay clients: spirituality as an indicator of personal growth," Procedia - Social and Behavioral Sciences, vol. 30, pp. 2117 -2123, Desember 2011.

[11] R. G. Tedeschi and L. G. Calhoun, "Posttraumatic growth: Conceptual foundations and empirical evidence," Psychological Inquiry, vol. 15, pp. 1-18, 2004.

[12] R. G. Tedeschi and L. G. Calhoun, "The Posttraumatic Growth Inventory: Measuring the positive legacy of trauma," Journal of Traumatic Stress, vol. 9, pp. 455-471, 1996.

[13] R. L. Piedmont and M. M. Leach, "Cross-cultural generalizability of the spiritual transcendence scale in India: Spirituality as a universal aspect of human experience," American Behavioral Scientist, vol. 45, pp. 1888-1901, September 2002.

[14] L. M. Edwards, R. H. Lapp-Rincker, J. L. Magyar-Moe, J. D. Rehfeldt, J. A. Ryder, and J. C. Brown, et al, "A positive relationship between religious faith and forgiveness: Faith in the absence of data?," Pastoral Psychology, vol. 50, pp. 147-152, Januari 2002.

[15] J. J. Exline, R. F. Baumeister, B. J. Bushman, W. K., Campbell, and E. J. Finkel, "Too proud to let go: Narcissistic entitlement as a barrier to forgiveness," Journal of Personality and Social Psychology, vol. 87, pp. 894-912, 2004.

[16] J. Tsang, M. E. McCullough, and W. T. Hoyt, "Psychometric and rationalization accounts of the religion-forgiveness discrepancy," Journal of Social Issues, vol. 61, pp.785-805, 2005.

[17] R. D. Enright, M. J. Santos, and R. Al-Mabuk, "The adolescent as forgiver," Journal of Adolescence, vol. 12, pp. 95-100, March 1989.

[18] R. L. Gorsuch and J. Y. Hao. "Forgiveness: An exploratory factor analysis and its relationship to religious variable," Review of Religious Research, vol. 34, pp. 333-347, June 1993.

[19] M. M. Poloma dan G. H. Gallup, Varieties of prayer, Philadelphia: Trinity Press International, 1999.

[20] M. E. McCullough, K. I. Pargament and C. E. Thoresen (Eds.), Forgiveness: Theory, research, and practice, New York: Guilford Press, 2000, pp. 17-40.

[21] P. L. Hill and M. Allemand, "Forgivingness and adult patterns of individual differences in environmental mastery and personal growth," Journal of Research in Personality, vol. 44, pp. 245-250. Elsevier Inc., April 2010.

[22] A. Laufer and Z. Solomon, "Posttraumatic symptoms and posttraumatic growth among Israeli youth exposed to terror incidents," Journal of Social and Clinical Psychology, vol. 25, pp. 429-447, April 2006.

[23] J. E. Milam, A. Ritt-Olsen, and J. B. Unger, "Posttraumatic growth among adolescents," Journal of Adolescent Research, 19, 192-204, 2004.

[24] J. E. Milam, A. Ritt-Olsen, S. Tan, J. B. Unger, and E. Nezami, "The September 11th 2001 terrorist attacks and reports of posttraumatic growth among a multi-ethnic sample of adolescents," Traumatology, vol. 11, pp. 233-246, Desember 2005.

[25] S. S. Park, "Exposure to community violence and aggressive beliefs in adolescents: Role of posttraumatic growth and developmental resources," Dissertation Abstracts International: Section B: The Sciences and Engineering, 2006, pp. 17-32.

[26] A. A.Vaughn, S. C. Roesch, and A. A. Aldridge, "Stress-related growth in racial/ethnic minority adolescents: Measurement structure and validity," Educational and Psychological Measurement, vol. 69, pp. 131-145, April 2009.

[27] L. Y. Thompson, C. R. Snyder, L. Hoffman, S. T. Michael, H. N. Rasmussen, and L. S. Billings, "Dispositional forgiveness of self, others, and situations," Journal of Personality, vol. 73, pp. 313-359, April 2005.

[28] R. M. Baron and D. A. Kenny, "The moderator-mediator variable distinction in social psychological research: Conceptual, strategic, and statistical considerations," Journal of Personality and Social Psychology, vol. 51, pp. 1173-1182, 1986.

[29] M. E. Sobel, "Asymptotic confidence intervals for indirect effects in structural equation models," Sociological Methodology, vol. 18, pp. 290-312, 1982.

[30] G. W. Sutton, K. C. McLeland, K. L. Weaks, P. E. Cogswell, and R. N. Miphouvieng, "Does gender matter? Relationship of gender, spousal support, spirituality, and dispositional forgiveness to pastoral restoration," Pastoral Psychology, vol. 55, pp. 645-663, March 2007.

[31] L. C. Friedman, C. R. Barber, J. Chang, Y. L. Tham, M. Kalidas, M. F. Rimawi, M. F. Dulay, et al, "Self-blame, self-forgiveness, and spirituality in breast cancer survivors in a public sector setting," Journal of cancer education : the official journal of the American Association for Cancer Education, vol. 25, pp. 343-8, 2010. 
[32] J. M. Schultz, B. A.Tallman, and E. M. Altmaier, "Pathways to posttraumatic growth: The contributions of forgiveness and importance of religion and spirituality," Psychology of Religion and Spirituality, vol. 2, pp. 104-114, May 2010.

[33] A. H. S. Harris and C. Thoresen, "Forgiveness, unforgiveness, health, and disease, " in Handbook of forgiveness, E. L. Worthington, Jr. (Ed.), New York: Routledge, 2005, pp. 321-334.

[34] L. Toussaint and J. R. Webb, "Theoretical and empirical connections between forgiveness, mental health, and well-being," in Handbook of forgiveness, E. L. Worthington, Jr. (Ed.), New York: Routledge, 2005 , pp. $349-362$.

[35] A. M. David, E. G. Kathryn , S. C. Jocelyn and P. K.. Ryan, "Posttraumatic growth among children and adolescents: A systematic review," Clinical Psychology Review, vol. 31, pp. 949-964, August2011.

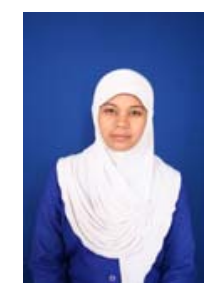

Hafnidar is Lecturer with the Malikussaleh University, Lhokseumawe, Aceh (Indonesia).

She is master student of Department of Psychology, Asia University Taiwan, Master Student.Department of Psychology, Diponegoro University, Central Java (Indonesia), S. Psi Her research is concerned with forgiveness, specifically what forgiveness is and why people forgive.



Li-jung (Ike) Chang is associate professor of Asia University Taiwan

$\mathrm{He}$ got $\mathrm{PhD}$ from Department of Social and Personality Psychology, University of Georgia(USA), MS from Department of Social and Personality Psychology, University of Georgia(USA), Department of Health Education and Behavioral Science, National Taiwan Normal University, and BA from Department of Psychology, Fu-jen University

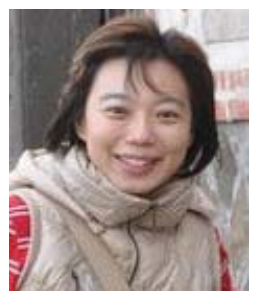

Lin. Hsiu-Chen is Assistant Professor of Asia University Taiwan. She got Ph.D in Special Education, The University of Texas at Austin 